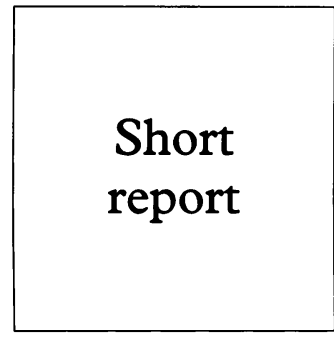

\title{
Gonorrhoea: auxotypes, serovars, and clinical manifestations among female sex workers from Kinshasa, Zaïre
}

\author{
L Mukenge-Tshibaka, M Alary, E Van Dyck, M Laga, N Nzila
}

The main question in this paper was to look at the distribution of auxotypes and serovars of Neisseria gonorrhoeae and check whether they correlate with clinical symptoms/signs among female sex workers (FSW) from Kinshasa, Zaïre. The subjects were 1233 FSW enrolled in a cross sectional study on STDs and HIV infection in 1988; 771 of them were followed prospectively for a median duration of 23 months. At each visit, clinical symptoms and signs of cervicitis were recorded and the subjects were screened for gonococcal and chlamydial infection. The predominant auxotypes were prototrophic $(35.2 \%)$, proline requiring $(29.6 \%)$, and proline requiring phenylalanine inhibition (19\%). Serovars 1A-6 (42.5\%) and 1B-1 (16.7\%) were the commonest. Infection with auxotype prototrophic and phenylalanine inhibition (Proto/Phenali) was significantly associated with both mucopurulent cervicitis and pelvic inflammatory disease; (OR = $8.9 ; p=0.002$ and $O R=19.9 ; p=0.002 ;$ respectively). Despite the few associations found in this study, there was no clear pattern linking clinical manifestations to auxotype/serovar profiles. (Genitourin Med 1997;73:564-566)

Keywords: Neisseria gonorrhoeae; auxotypes; serovars; symptoms/signs

\section{Introduction}

It is well known that the epidemiology of Neisseria gonorrhoeae infection is influenced by auxotypes and serovars that are structurally and antigenically different. ${ }^{2}$ Geographical, temporal, and ethnical variations of auxotypes and serovars have been documented. ${ }^{34}$ In industrialised countries, the availability of serotyping has allowed detailed epidemiological and clinical studies of gonococcal infection over the past 20 years. However, only a few studies have been conducted in developing countries of tropical Africa on gonococcal resistance according to the serological classification of isolates. ${ }^{5}$ To our knowledge, no survey has been published from this part of the world on the expression of gonococcal disease according to the phenotype of isolates. This study was undertaken to look at the distribution of auxotypes and serovars of $N$ gonorrhoeae and to check whether they correlate with clinical symptoms/signs among female sex workers from a developing country, Zaïre.

\section{Methods}

In 1988, 1233 female sex workers were enrolled in a cross sectional study, screened for STDs and HIV antibodies in Matonge, Kinshasa by the Projet/SIDA Zaïre. This population has been described extensively elsewhere. ${ }^{6}$ Briefly, 771 of these women were followed prospectively, once every month for a median duration of 23 months (range 3-36 months). Demographic characteristics, medical and sexual history were recorded by a nurse in a face to face interview. The nurse also recorded information about urogenital symptoms (vaginal discharge, lower abdominal pain, and vulvar itching). A physician performed a gynaecological examination to record clinical signs (vaginal discharge, cervical motion tenderness, cervix erosion, and mucopurulent cervicitis).

Samples from gynaecological examination were tested for $N$ gonorrhoeae, Chlamydia trachomatis, Trichomonas vaginalis, and yeasts. Gonococci were isolated on modified ThayerMartin medium incubated in a candle extinction jar at $35^{\circ} \mathrm{C}$ for $24-48$ hours. Isolates were identified on the basis of typical colony morphology, oxidase reaction, and sugar utilisation patterns. Strains were tested for their requirements for proline, arginine, hypoxanthine, uracil, methionine, amino acids, vitamins, and for inhibition by phenylalanine according to the auxotyping method described by Hendry and Stewart. ${ }^{2}$ For serotyping, strains were tested by coagglutination with 0 monoclonal antibodies. The Knapp's serovar nomenclature was used. ${ }^{1}$

Data analysis concerned 1094 infective episodes with $N$ gonorrhoeae; 286 of them were diagnosed at enrolment whereas 808 were incident episodes (defined as a patient presenting a positive test at a follow up visit with a negative test at the previous visit or with a suitable treatment in the event of a positive test at the previous visit). Statistical analysis to compare the prevalence of recorded symptoms/ signs measured according to different auxotypes, serovars, and auxotype/serovar classes was performed using $\chi^{2}$. When the proportions were significantly different, we calculated the

Centre de recherche,
Hôpital du Saint-
Sacrement, Québec,
Canada
L Mukenge-Tshibaka
M Alary
Department of
Infection and
Immunity, Institute of
Tropical Medicine,
Antwerp, Belgium
E Van Dyck
M Laga
Projet Sida, Ministry
of Health, Kinshasa,
Zaïre
N Nzila
Correspondence to:
Michel Alary, MD, PhD,
Centre de recherche Hôpital
du Saint-Sacrement 1050
chemin Ste-Foy, Québec,
Canada G1S 4L8.
Accepted for publication
28 August 1997


Table 1 Auxotypes, serovars of Neisseria gonorrhoeae among female sex workers from Kinshasa, Zaïre

\begin{tabular}{|c|c|c|c|}
\hline $\begin{array}{l}\text { Auxotype } \\
(n=622)\end{array}$ & $\begin{array}{l}\text { No of strains } \\
\text { (\%) }\end{array}$ & $\begin{array}{l}\text { Serovar } \\
(n=659)\end{array}$ & $\begin{array}{l}\text { No of strains } \\
(\%)\end{array}$ \\
\hline $\begin{array}{l}\text { Proto } \\
\text { Proto/Phenal }^{i} \\
\text { Pro }^{-} \\
\text {Pro }^{-} / \mathrm{AA}^{-} / \mathrm{Phenal}^{\mathrm{i}} \\
\text { Pro-}^{-} / \mathrm{Phenal}^{\mathrm{i}} \\
\text { Pro }^{-} / \mathrm{Arg}^{-} \\
\text {Pro }^{-} / \mathrm{Hypx}^{-} / \mathrm{Ura}^{-} \\
\text {Pro }^{-} / \mathrm{Vit}^{-} \\
\text {Arg }^{-} \\
\text {Pro }^{-} / \mathrm{Arg}^{-} / \mathrm{AA}^{-} \\
\text {Met }^{-} \\
\text {AA }^{-}\end{array}$ & $\begin{aligned} 219(35 \cdot 2) \\
11(1 \cdot 8) \\
184(29 \cdot 6) \\
1(0 \cdot 2) \\
118(19 \cdot 0) \\
76(12 \cdot 2) \\
1(0 \cdot 2) \\
2(0 \cdot 3) \\
3(0 \cdot 5) \\
1(0 \cdot 2) \\
1(0 \cdot 2) \\
1(0 \cdot 2)\end{aligned}$ & $\begin{array}{l}\text { Serogroup IA } \\
\text { IA0 } \\
\text { IA1 } \\
\text { IA2 } \\
\text { IA3 } \\
\text { IA4 } \\
\text { IA5 } \\
\text { IA6 } \\
\text { IA8 } \\
\text { IA17 } \\
\text { Serogroup IB } \\
\text { IB0 } \\
\text { IB1 } \\
\text { IB2 } \\
\text { IB3 } \\
\text { IB4 } \\
\text { IB5 } \\
\text { IB6 } \\
\text { IB7 } \\
\text { IB8 } \\
\text { IB17 } \\
\text { IB23 } \\
\text { IB24 } \\
\text { Not typable }\end{array}$ & $\begin{aligned} & 348(52 \cdot 8) \\
& 2(0 \cdot 3) \\
& 12(1 \cdot 8) \\
& 12(1 \cdot 8) \\
& 2(0 \cdot 3) \\
& 21(3 \cdot 2) \\
& 8(1 \cdot 2) \\
& 280(42 \cdot 5) \\
& 9(1 \cdot 40) \\
& 2(0 \cdot 3) \\
& 273(41 \cdot 4) \\
& 7(1 \cdot 0) \\
& 110(16 \cdot 7) \\
& 5(0 \cdot 8) \\
& 34(5 \cdot 2) \\
& 7(1 \cdot 0) \\
& 17(2 \cdot 6) \\
& 15(2 \cdot 3) \\
& 67(10 \cdot 2) \\
& 2(0 \cdot 3) \\
& 1(0 \cdot 2) \\
& 1(0 \cdot 2) \\
& 7(1 \cdot 0) \\
& 38(5 \cdot 8)\end{aligned}$ \\
\hline
\end{tabular}

Proto = prototrophic; Phenal $^{\mathrm{i}}=$ phenylalanine inhibition $; \mathrm{Pro}^{-}=$proline requiring, $\mathrm{AA}^{-}=$amino acids requiring; $\mathrm{Arg}^{-}=$arginine requiring; $\mathrm{Hypx}^{-}=$hypoxanthine requiring; Ura ${ }^{-}=$uracil acids requiring; Arg $^{-}=$arginine requiring; Hypx
requiring; $^{-}$Vit $^{-}=$vitamins requiring; Met $^{-}=$methionine requiring.

odds ratios and $p$ values using a $2 \times 2$ table comparing each auxotype/serovar with all other considered together (Fisher's bilateral exact test). When significant associations were found in crude data, we performed analysis restricted to women not infected by $C$ trachomatis. Finally, we calculated the prevalence of auxotype/serovar classes every 6 months during the study period, and we limited comparison (using $\chi^{2}$ ) to the first two 6 month periods, since the majority of infections occurred in the first year.

\section{Results}

Clinical symptoms/signs of cervicitis were recorded respectively in $542(87 \cdot 1 \%)$ of the 622 episodes with gonococcal auxotype data, and in $577(87.6 \%)$ of the 659 episodes with gonococcal serovar data.

As shown in table 1 , the predominant auxotypes identified were prototrophic (Proto), proline requiring (Pro'), proline requiring/ phenylalanine inhibition (Pro-/Phenali) and proline/arginine requiring (Pro-/Arg-). These four commonest strains accounted for $96 \%$ of infections. The three most frequent serovars which encompassed $69.4 \%$ of infections were $1 \mathrm{~A}-6,1 \mathrm{~B}-1$, and 1B-7. Of the 659 strains serotyped, $348(52 \cdot 8 \%)$ were serogroup $1 \mathrm{~A}$ $273(41.4 \%)$ belonged to serogroup $1 \mathrm{~B}$, and $38(5 \cdot 8 \%)$ strains were ungroupable.

Combining the two classification systems, a total of 63 distinct auxotype/serovar classes were identified. The prevalence of the majority of these classes remained stable over the study period with the exception of Proto/1B-7 and Pro-/1A-6 classes that had changed dramatically in the second 6 months. The former was increased by a factor of 5 (from $4.6 \%$ to $23.6 \% ; \mathrm{p}<0.01$ ) and the second decreased very significantly (from $26 \cdot 1 \%$ to $10.6 \%$; $\mathrm{p}<0.01$ ).

Table 2 summarises the prevalence of recorded clinical symptoms/signs according to different auxotypes. Mucopurulent cervicitis (MPC) was more common in women infected with auxotype Proto/Phenal ${ }^{\mathrm{i}}$ than in women with all other strains; (5/10 (50\%) women infected with auxotype Proto/Phenal ${ }^{\mathrm{i}}$ had MPC $v 54 / 532(10.2 \%)$ women infected with all other auxotypes $(O R=8.9 ; p=0.002)$ ). Women infected with the same Proto/Phenal auxotype had more pelvic inflammatory disease (PID) than those infected with all other strains $(50 \%$ of the women infected with this auxotype had PID $v 4.8 \%$ for all other auxotypes $(O R=19.9 ; p=0.002)$ ). When we restricted analysis to women without chlamydial infection, MPC and PID remained significantly associated with auxotype Proto/Phenali.

None of the symptoms/signs was significantly associated with any particular serovar. However, serovar 1B-7 was significantly associated with the absence of signs (44/64 $(68.8 \%)$ women infected with serovar 1B-7 did not present any sign $v 229 / 513(44.6 \%)$ for all other serovars $(O R=2 \cdot 2 ; p=0.003)$ ).

\section{Discussion}

Our data show that the most frequent auxotypes were prototrophic and proline requiring. We noticed that the predominance of these two auxotypes was also reported elsewhere in Africa (Gabon) and in several studies performed in America and Europe. ${ }^{5-8}$ However, auxotypes Arg $\mathrm{Hyp}^{-} \mathrm{Ura}^{-}$and $\mathrm{Pro}^{-} \mathrm{Cit}$ Ura $^{-}$Hypx which have been isolated in Europe and America were not isolated in our study population. We also found auxotype Pro-Phenali very frequent $(19 \%)$. This auxotype was not isolated in other studies of which

Table 2 Prevalence of clinical symptoms and signs of Neisseria gonorrhoeae infection according to auxotype among female sex workers from Kinshasa, Zaire

\begin{tabular}{|c|c|c|c|c|c|c|c|}
\hline & \multicolumn{7}{|c|}{$\%$ of women with symptom or sign by auxotype } \\
\hline & $\begin{array}{l}\text { Proto } \\
(n=191)\end{array}$ & $\begin{array}{l}\text { Proto/Phenal } \\
(n=10)\end{array}$ & $\begin{array}{l}\text { Pro }^{-} \\
(n=161)\end{array}$ & $\begin{array}{l}\text { Pro- }^{-} \text {Phenal } \\
(n=105)\end{array}$ & $\begin{array}{l}\text { Pro- } / \text { Arg }^{-} \\
(n=63)\end{array}$ & $\begin{array}{l}\text { Others } \\
(n=12)\end{array}$ & $p^{*}$ Value \\
\hline \multicolumn{8}{|l|}{ Symptoms: } \\
\hline $\begin{array}{l}\text { Vaginal discharge } \\
\text { Lower abdominal pain } \\
\text { Vulvar itching }\end{array}$ & $\begin{array}{l}17 \cdot 3 \\
27 \cdot 8 \\
18 \cdot 3\end{array}$ & $\begin{array}{l}10 \cdot 0 \\
50 \cdot 0 \\
10 \cdot 0\end{array}$ & $\begin{array}{l}15 \cdot 5 \\
27 \cdot 3 \\
22 \cdot 4\end{array}$ & $\begin{array}{r}5 \cdot 7 \\
35 \cdot 2 \\
15 \cdot 2\end{array}$ & $\begin{array}{l}15 \cdot 9 \\
39 \cdot 7 \\
17 \cdot 5\end{array}$ & $\begin{array}{l}16 \cdot 7 \\
25 \cdot 0 \\
25 \cdot 0\end{array}$ & $\begin{array}{l}0.14 \\
0.22 \\
0.68\end{array}$ \\
\hline \multicolumn{8}{|l|}{ Signs: } \\
\hline $\begin{array}{l}\text { Vaginal discharge } \\
\text { Cervix erosion } \\
\text { Mucopurulent cervicitis } \\
\text { Cervical motion tenderness }\end{array}$ & $\begin{array}{r}42 \cdot 4 \\
13 \cdot 0 \\
9 \cdot 9 \\
7 \cdot 9\end{array}$ & $\begin{array}{r}70 \cdot 0 \\
0.0 \\
50.0 \\
10 \cdot 0\end{array}$ & $\begin{array}{r}44 \cdot 7 \\
11 \cdot 8 \\
11 \cdot 2 \\
6 \cdot 8\end{array}$ & $\begin{array}{r}41 \cdot 9 \\
6 \cdot 7 \\
3 \cdot 8 \\
11 \cdot 4\end{array}$ & $\begin{array}{r}58 \cdot 7 \\
9 \cdot 5 \\
19 \cdot 0 \\
7 \cdot 9\end{array}$ & $\begin{array}{r}50 \cdot 0 \\
8 \cdot 3 \\
8 \cdot 3 \\
8 \cdot 3\end{array}$ & $\begin{array}{r}0.14 \\
0.48 \\
<0.01 \\
0.86\end{array}$ \\
\hline
\end{tabular}

Proto = prototrophic; Phenal $^{i}=$ phenylalanine inhibition; Pro $^{-}=$proline requiring; Arg $^{-}=$arginine requiring; Others $=$different infrequent auxotypes. $p^{\star}$ Value from $\chi^{2}$ test on the $2 \times 6$ table comparing the proportions of women with each specific symptom/sign by auxotype. 
we are aware since strains were not tested for the inhibitory activity of phenylalanine.

In industrialised countries, the serovars of serogroup B seem to predominate whereas in our study, as in Gabon, more than half of the strains were serogroup A. Indeed, in Spain, serovars of serogroup B accounted for $93.5 \%$ of all strains. ${ }^{8}$ This serogroup also predominated in Canada $(66.8 \%)$ and in Sweden $(70 \%) .^{29}$

We observed dramatic changes in the gonococcal population infecting the cohort over the study period with the introduction of new strains and loss of other strains. This has been previously reported. ${ }^{3}$ The significant loss of certain strains supports the notion of gonococcal strain specific acquired (partial) immunity, as proposed by Plummer and colleagues who reported that women experiencing an infection with a specific gonococcal serovar were at 2- to 10 -fold reduced risk of reinfection with the same strain. ${ }^{10}$

Despite the fact we made multiple comparisons, we found that only a few auxotypes/ serovars of $N$ gonorrhoeae were significantly associated with clinical manifestations of gonococcal infection and the strength of some associations may suggest that they did not occur by chance only. Indeed, we found that auxotype Proto/Phenali was strongly associated with both MPC and PID. However, this apparently increased virulence of auxotype Proto/Phenali should be interpreted with caution because of the small number of women infected with this strain (only 11 of the 622 auxotypes) and the impossibility of comparing our results with those reported by other authors since this auxotype was not isolated in their studies.

In summary, we did not identify many associations between auxotypes/serovars of $N$ gonorrhoeae and symptoms/signs. To compare the associations we observed and to obtain a better understanding of the epidemiology of gonococcal infection in developing countries, there is a need for additional studies using similar methods distinguishing between strains of $N$ gonorrhoeae (including testing for phenylalanine inhibition) in areas where the same isolates can be found.

This study was supported by the European Community (EC) Programme on Science and Technology for Development, the EC AIDS Task Force, the Belgian Fund for Scientific Research (NFWO), the Rockfeller Foundation, the American Foundation for AIDS Research, and the World Organisation Global Programme on Aids.

Dr Alary is a research scholar of the National Health Research and Development Program of Health Canada (6605-4157-48A) and the Fonds de la recherche en Santé du Québec (930073-103).

The authors thank the staff of Matonge Centre; the service d'Hygiène de Kinshasa; the staff of the support laboratory of project Sida, Edidi and Mokwa.

1 Knapp JS, Tam MR, Nowinski RC, Holmes KK, Sandstrom EG. Serological classification of Neisseria gonorrhoeae with use of monoclonal antibodies to gonococcal outer membrane protein 1. F Infect Dis 1984;150:44-9.

2 Hendry AT, Stewart IO. Auxanographic grouping and typing of Neisseria gonorrhoeae. Can 7 Microbiol 1979;25. 512-21.

3 Knapp JS, Holmes KK, Bonin P, Hook E. Epidemiology of gonorrhea: distribution and temporal changes in auxotype/serovar classes of Neisseria gonorrhoeae. Sex Transm Dis 1987;14:26-32.

4 Noble RC, Parekh MC. Changes in the prevalence of auxotypes of Neisseria gonorrhoeae among black and white patients attending a clinic for sexually transmitted diseases. Sex Transm Dis 1983;10:14-7.

5 Peeters FM, Frost EH, Ossari SA, Ivanoff B. Antibiotic susceptibility in relation to serogroup and auxotype of Neisseria gonorrhoeae isolates from Gabon. Sex Transm Dis 1986;14:130-4.

6 Laga M, Manoka A, Kivuvu M, Malele B, Tuliza M, Nzila $\mathrm{N}$, et al. Non-ulcerative sexually transmitted diseases as risk factors for HIV-1 rensmission in women. Results from a cohort study. AIDS 1993;7:95-102.

7 Brunham RC, Plummer F, Slaney L, Rand F, DeWitt W. Correlation of auxotype and protein I type with expression of disease due to Neisseria gonorrhoeae. F Infect Dis 1985;152:339-43

8 Vasquez F, Palacio V, Vasquez JA, Berron S, Gonzalez A Lianeza SS. Gonorrhoea in women prostitutes: clinica data and auxotypes, serovars, plasmid contents of PPNG, and susceptibility profiles. Sex Transm Dis 1990; 18:5-9.

9 Ruden AK, Backman M, Bygdeman S, Jonsson A, Ringertz O, Sandstrom E. Gonorrhoea in heterosexual men. Correlation between gonococcal W serogroup, Chlamydia relation between gonococcal W serogroup, Chlamydia trachomatis and objective

10 Plummer FA, Simonsen JN, Chubb H, Slaney L, Kimata J, Bosire M, et al. Epidemiologic evidence for the development of serovar-specific immunity after gonococcal infection. $\mathcal{F}$ Clin Invest 1989;83:1472-6. 